\title{
LA CREACIÓN DEL MITO DE LA MANGA DEL MAR MENOR A TRAVÉS DE LA PROMOCIÓN TURÍSTICA DE NO-DO ${ }^{1}$
}

\author{
Isabel Durante Asensio \\ Universidad de Murcia \\ https://orcid.org/0000-0001-8625-7855 \\ José Javier Aliaga Cárceles \\ Universidad de Murcia \\ https://orcid.org/0000-0003-0524-0823
}

\section{RESUMEN}

La entidad de los Noticiarios y Documentales (NO-DO) fue la encargada de construir una imagen identitaria del país acorde a los intereses políticos del Régimen. En el caso del turismo, fue a partir del desarrollismo cuando ocupó un lugar destacado. En este contexto, La Manga del Mar Menor se sumó a los contenidos de la promoción turística que las cámaras de NO-DO generaron, al tiempo que reflejaron el proceso de transformación de la zona, pasando de un ámbito casi salvaje a un paraíso turístico de primer orden. Este semblante de La Manga se cimentó en una serie de elementos que constituyeron la iconografía cinematográfica de este enclave.

Palabras clave: Turismo; La Manga; NO-DO; desarrollismo; sol y playa.

The devise of the myth of La Manga del Mar Menor through the tourist promotion of NO-DO

Fecha de recepción: 1 de junio de 2018

Fecha de aceptación: 30 de enero de 2019

Departamento de Historia del Arte. Universidad de Murcia. Campus de La Merced. 30001 MURCIA (España).E-mail: idurante@um.es, josejavier.aliaga@um.es

1 Esta investigación forma parte del Proyecto de Investigación I+D Excelencia "El Documental de Arte en España (1939-1975)", financiado por el Ministerio de Economía, Industria y Competitividad, referencia: HAR2017-83666-P (MINECO), y se ha realizado al amparo de la Ayuda para la Formación del Profesorado Universitario, referencia: FPU16/00799 (MECD). 


\begin{abstract}
The entity of Noticiarios y Documentales (NO-DO) was commissioned to build an identity image of the country according to the political interest of the Regime. In tourism case, it was when the development took place, when NO-DO occupied a prominent place. In this context, La Manga del Mar Menor was added to the contents of the tourism promotion that the NO-DO cameras generated, while the transformation process of the area was also reflected, going from a wild area to a main touristic paradise. This appearance of La Manga was based on different elements that constitute the cinematographic iconography of this enclave.
\end{abstract}

Keywords: Tourism, La Manga, NO-DO, developmentalism; sun and beach.

\title{
1. INTRODUCCIÓN
}

La Manga es una restinga situada en la Región de Murcia que a finales de los años sesenta se convirtió en un espacio emblemático como destino turístico. Una circunstancia favorecida por la producción de NO-DO que contribuyó a la construcción identitaria de la zona desde la década de los cincuenta en la que hizo su primera aparición hasta 1981, año en que desapareció la entidad. En este contexto, las cámaras de este organismo fueron las encargadas de registrar el proceso de transformación de la zona que partió de un modelo tradicional, donde la pesca era la actividad principal, para convertirse en un ejemplo del desarrollismo y del crecimiento urbanístico ligado a los intereses de promoción turística que afloraron en la España de esa década. Esta circunstancia, en el caso concreto de La Manga, se consolidó en los años posteriores con la ampliación de la oferta hotelera, deportiva y de servicios.

El pueblo de pescadores dio paso a un lugar privilegiado para un turismo nacional e internacional que vio, desde pronto, las ventajas de este lugar para los períodos vacacionales por su clima, su bajo coste y sus favorables condiciones naturales. Por tanto, las políticas sobre turismo encontraron en La Manga una opción con características específicas que la diferenciaban de otras zonas. Las particularidades que definían La Manga entroncaban con las ideas de paraíso, tranquilidad y descanso, aspectos alejados de la masificación y el trasiego de otras zonas como Mallorca, la Costa del Sol o la Costa Brava. En este orden de cosas, las cámaras oficiales fueron determinantes en la creación del mito.

Desde 1943, cuando los reportajes del NO-DO llegaron a las salas de cine, los contenidos de las imágenes estuvieron al servicio del ideario político del régimen franquista, encargado de construir una identidad visual del país siguiendo las premisas de su discurso: la recuperación del «pasado glorioso», la exaltación de la tradición, el valor del ejército, la religión, el reconocimiento de la familia como único modelo válido dentro de la sociedad y la implementación de nuevos procesos industriales que plasmarían la modernización de los sistemas de producción, entre otros. Estas cuestiones estuvieron presentes a lo largo de toda la dictadura, si bien es cierto que en determinadas etapas se incluyeron otros asuntos 
que comenzaron a tener importancia. Este fue el caso del turismo, pues no sería hasta los años sesenta cuando se convirtiera en una constante en el noticiario y los documentales.

A este respecto, en los últimos años son numerosos los estudios que han puesto de relieve esta circunstancia, es decir, el papel fundamental que desempeñó el cine de estado en la construcción iconográfica de los diferentes destinos turísticos de España (Zamarreño, 2010; Brotons, Murray-Mas y Blázquez-Salom, 2016; Zamarreño y De los Reyes, 2017). No obstante, el caso de La Manga del Mar Menor no ha sido abordado hasta la fecha desde esta perspectiva. Sin embargo, su importancia es destacable, ya que ocupa buena parte de los materiales rodados en la Región de Murcia por el NO-DO. En consecuencia, los objetivos de este trabajo se concretan en recoger, clasificar y analizar estas imágenes cinematográficas con el fin de aproximarnos al semblante que se dio de La Manga en ese momento, al tiempo que podemos comprobar cómo fue el desarrollo urbanístico y turístico de la zona. Este planteamiento genera una serie de interrogantes, tales como: ¿cuál fue el papel que el NO-DO desempeño en la representación de La Manga en el imaginario colectivo? ¿cómo contribuyó este a la promoción de la zona? o ¿de qué elementos se sirvió para exaltar su potencial turístico?

Así las cosas, el estudio permitirá valorar las variables cinematográficas utilizadas en la construcción de la imagen identitaria de esta zona del litoral murciano, al tiempo que posibilitará el análisis del desarrollo turístico y la expansión urbanística de un entorno natural como paradigma del desarrollismo. Además, el repertorio confeccionado a tal efecto contribuirá a resaltar la importancia de La Manga dentro de la representación fílmica en el contexto regional.

\section{LA INCLUSIÓN DEL TURISMO EN LA CINEMATOGRAFÍA OFICIAL DEL FRANQUISMO (NO-DO)}

La creación de NO-DO se materializó en un acuerdo de la Vicesecretaria de Educación Popular de la Falange Española Tradicionalista (FET) y de la Juntas de Ofensiva Nacional Sindicalista (JONS), el 29 de septiembre de $1942^{2}$, pero no llegó a las pantallas hasta el 4 de enero de 1943. Desde los inicios, el noticiario impuso la obligatoriedad de su exhibición en todas las salas del país, mientras que los documentales no respondieron a esta premisa. A este respecto, el noticiario, cumpliendo su principal cometido, la función propagandística, fue el encargado de registrar y difundir la actualidad siguiendo su carácter de seriación, al tiempo que garantizó la rapidez en la transmisión de los sucesos. Por su parte, el documental asumió un alcance más divulgativo, no exento de carga ideológica que planteó la necesidad de plasmar las cualidades intrínsecas a la nación haciendo referencia a aspectos sociales, económicos, culturales y artísticos. Así mismo, relegó a un segundo plano la esfera política (Matud, 2008: 526).

Por otro lado, es interesante destacar la diversificación que hizo de sus actividades la entidad. En el campo del noticiario, se concretó en la escisión de dos secciones, A y B,

2 Tras este acuerdo, se promulga la Orden de 17 de diciembre de 1942, publicada en BOE con fecha de 22 de diciembre de ese mismo año, «disponiendo la proyección obligatoria y exclusiva del Noticiario Cinematográfico Español y concediendo la exclusividad absoluta de reportajes cinematográficos a la entidad editora del mismo, Noticiario y Documentales Cinematográficos No-Do», p. 10.444. 
para los materiales rodados -a partir del número 20, del 17 de mayo de 1943-, a las que, más tarde, -a partir del número 926, del 3 de octubre de 1960-, se le añadió la serie C (Rodríguez Tranche y Sánchez-Biosca, 2005). En el ámbito del documental, sin embargo, la división respondió a una cuestión técnica. Por un lado, se sistematizaron los realizados en blanco y negro, y por otro, los de color. Por último, hay una tercera categoría en la que se encuadrarían las ediciones especiales correspondiente a revistas periódicas como Imágenes, puesta en marcha en enero de 1945, con una periodicidad semanal ${ }^{3}$. Esta clasificación nos ayuda a entender la ingente producción cinematográfica de NO-DO, así como a situar los materiales objeto de estudio. Aunque hay que señalar que esta ordenación no responde a una condición aleatoria, sino a motivaciones concretas: la inclusión de una tercera sección, la $\mathrm{C}$, en el apartado noticias viene determinada por la necesidad del noticiario de competir con la televisión, que en ese momento fue ganando terreno en el panorama audiovisual. También, en este sentido, se recurrió al uso del color y a modificar la edición para poder ser exhibido en un formato más pequeño (Del Amo, 1993).

En cuanto a los contenidos recogidos en las noticias de NO-DO, R. Tranche y SánchezBiosca realizan una propuesta de categorías, que sigue el planteamiento de Robert J. Schilh, en la que articulan dos grandes bloques; el primero de ellos correspondería a las denominadas noticias duras, caracterizadas por presentar sucesos de actualidad que eran transmitidos de manera instantánea, mientras que el segundo englobaría el de las noticias blandas, más numerosas en su producción, y que no implican ese rango de actualidad. Aunque está clasificación es para nuestro objeto de estudio demasiado somera y no nos permite analizar el alcance y calado de las noticias, pues habría que sumar otros aspectos relacionados con la duración, el posicionamiento dentro del programa general y la asiduidad del asunto (Rodríguez Tranche y Sánchez-Biosca, 2005). NO-DO, así, generó una serie de secciones temáticas fijas en las que incluyó noticias de un perfil similar (Rodríguez, 1999). Destacan las referidas al Régimen, con claras alusiones a la historia y a la figura de Franco; a las relaciones internacionales; y a los acontecimientos sociales, religiosos, festivos y deportivos, abundantes en el caso de la Región de la Murcia.

A principios de los años cincuenta, España emprendió una tímida apertura internacional que se consolidó en el Plan de Estabilización de 1959. Esta circunstancia se constata en la inclusión del turismo en el ámbito cinematográfico, un asunto que comienza a gestarse en este momento. No podemos obviar que el desarrollo turístico a partir de la creación del Ministerio de Información y Turismo, en 1951, vio en NO-DO un vehículo idóneo para difundir las directrices de las políticas en materia de turismo, confluyendo, en este sentido, en los materiales fílmicos producidos por el organismo los dos principales intereses que dieron nombre a este ministerio.

No obstante, «en estos años, a Franco le incomodaba la idea de fomentar el turismo; hasta finales de la década de 1950 no empezó a aceptar tácitamente que los beneficios económicos compensaban los costes sociales» (Pack, 2009: 75). Por ello, vemos cómo entre 1950 y 1958 tan solo se realizaron sobre turismo once piezas, cuando la producción

3 Las cifras sobre los materiales cinematográficos, según los datos de Filmoteca Española, son: 4.016 noticias para España, 216 documentales en blanco y negro, 498 documentales en color y 1.219 números de la edición Imágenes. A ello habría que sumar los realizados para América Hispana, Portugal, Brasil, y las secciones IBERIA y cultura. 
total superaba las ochocientas. Los sesenta, por su parte, supusieron un importante incremento de películas turísticas registradas por las cámaras oficiales. Entre 1963 y 1969, uno de cada once documentales giraba en torno a las políticas de turismo (Pack, 2009). Estas cifras revelan como la década de los sesenta va a ser prolífica en la producción de este tipo de material cinematográfico con efectos propagandísticos. Los intereses que ligaron el turismo a lo fílmico se basan en que el cine se erigió como una herramienta eficaz de difusión a nivel nacional e internacional. En este momento, se emprendió una serie de acciones por parte de la Administración del Estado encaminadas a la ordenación y fomento del sector en el marco de los Planes de Desarrollo.

Así, el cine contribuyó a configurar e implementar diversas zonas turísticas, al tiempo que consolidó la idea de «marca de destino», un concepto basado en las peculiaridades endógenas del territorio con cualidades diferenciadoras (Huertas, 2014). En general, los valores perseguidos por la creación de esa marca trascendieron los aspectos definidores de lo territorial para la consecución de otros, alejados de lo estrictamente turístico y relacionados con lo social, concretándose en una serie de aspectos positivos que ayudaron a construir «la mirada turística» (Urry, 1990). Esta mirada estuvo pertrechada por la imagen cinematográfica que cimentó ese objetivo en las producciones de ese momento. Es evidente que el cine se erigió como el medio de masas que más promovió el turismo (Riley y Van Doren, 1992), una herramienta ideal para construir un imaginario colectivo que, en ocasiones, hizo de ciertos destinos espacios propicios para la creación de un mito que atrajera a los visitantes.

En este orden de cosas, el Mediterráneo se convirtió en un escaparate para mostrar las cualidades de unas zonas caracterizadas, fundamentalmente, por el sol y la playa, dos elementos potenciadores del turismo español. Fueron varios los emplazamientos consignados a construir ese ideario común del Mediterráneo, aunque cada uno de ellos con unas especificidades propias. Por supuesto, Mallorca, y el resto de las Islas Baleares, fueron uno de los lugares en los que más temprano concurrió esta circunstancia. Ya en el primer tercio del siglo XX aparece esa intención de forjar una idea de paraíso en la «isla de la calma», aunque sería en los años cincuenta y sesenta, momento que nos ocupa, cuando se dé un cambio de paradigma que entroncó con ese auge de la promoción turística de grandes instalaciones hoteleras, vida nocturna y hamacas junto al mar, relegando la idea de tranquilidad y tradición (Brotons, Murray-Mas y Blázquez-Salom, 2016). En el caso de la Costa Brava, que se entendió como una especie de continuación de la concurrida Costa Azul francesa, su foco de interés también fue el sol y la playa. En cuanto a la Costa del Sol sucedió lo mismo, sobre todo a partir de la década de los sesenta, convirtiéndose en uno de los espacios claves del boom turístico (Zamarreño, Ruiz y De los Reyes, 2017). En la Costa Blanca a finales de los cincuenta se produjo también un importante crecimiento del turismo. Uno de los ejemplos más relevantes de este fenómeno fue Benidorm, símbolo del turismo de masas en la segunda mitad del siglo XX, que puede establecer ciertas concomitancias con lo que sucedería a finales de los años sesenta en La Manga del Mar Menor. Este nuevo orden que se da en la España desde finales de los años cincuenta supone una renovación de las estructuras de promoción que en los años de la autarquía se rigió por el lema Spain is Different que encerraba una propuesta de tópicos y folclore vinculados a la españolidad (Afinoguénova y Martí-Olivella, 2008). 


\section{LA MANGA DEL MAR MENOR COMO MITO TURÍSTICO}

La singularidad de La Manga radica en su enclave y su configuración territorial. Se trata de una restinga de 24 kilómetros de longitud y 500 metros de anchura media que da lugar al Mar Menor y que se comunica con el Mediterráneo mediante golas, haciendo de este lugar uno de los mares más peculiares de la costa mediterránea.

No fue hasta los años sesenta cuando La Manga comenzó a transformarse para pasar de un estado natural casi intacto a una zona en expansión que cristalizaría en las décadas sucesivas. Hasta esa fecha su actividad económica se basó, principalmente, en la pesca tradicional de la que se abastecía este pueblo de pescadores que determinó su imagen. El desarrollismo trajo consigo un cambio de paradigma consustancial a los rasgos de modernidad que se respiraban en aquella época. El Plan de Ordenación y Urbanización sobre los terrenos de La Manga, publicado en junio de 1962, supuso un punto de inflexión en la ordenación de este territorio. Ese mismo año, solo un mes después, Manuel Fraga Iribarne, al frente del Ministerio incluyó La Manga en los Planes de Desarrollo Económico y Social. Este modelo de progreso se basó en la Ley de Zonas y Centros de Interés Turístico Nacional a partir de 1964. Evidentemente, este fomento del turismo evolucionó hacia un nuevo modelo económico y territorial en el Mediterráneo, algo que también se dio sólidamente en La Manga (Espejo, 2011).

Asimismo, en 1962 se reactivó la Comisión Interministerial de Turismo, que había sido fundada en 1954, y que diseñó un conjunto de planteamientos destinados a afianzar administrativamente la actividad turística, concretándose en las propuestas para un Plan Nacional de Turismo que, finalmente, no recogió los resultados de las ponencias realizadas por las distintas regiones. En cualquier caso, estos planteamientos se constituyeron como un instrumento de primer orden en el proceso de planificación territorial turística. Dentro de las propuestas dirigidas a potenciar el turismo de sol y playa se hizo hincapié en «la dinamización de zonas litorales poco afectadas todavía por el boom turístico y dotadas de buenas condiciones naturales: el Mar Menor (Murcia), la costa de Huelva, Peñíscola y Canarias» (Galiana y Barrado, 2006: 75). El resultado fue la aprobación de la Ley 197/1963, de 28 de diciembre, sobre Centros y Zonas de Interés Turístico Nacional ${ }^{4}$.

A mediados de 1960, las autoridades provinciales habían decido realizar un estudio sobre el futuro turístico de las playas murcianas que incluía asuntos como el estado de las vías de comunicación y la provisión de agua potable. La pretensión fue aclarar cuáles eran las fortalezas y debilidades de la zona a la hora de recibir visitantes. Ese informe fue presentado al Ministerio de Información y Turismo con la intención de adquirir un compromiso de apoyo a la idea de desarrollo y dinamización de la zona. Y así fue. La visita de la Comisión de Técnicos en Turismo de la Secretaría General en ese momento supuso una implementación a ese deseo de promoción turística (Andrés Sarasa, 1995).

Todas estas tentativas que se fueron fraguando durante los años sesenta se materializaron en la década de los setenta, una fecha en la que España vivió un momento de

4 Publicado en BOE, núm. 313, de 31 de diciembre de 1963, pp. 18226-18230. 
recesión en materia turística. A partir de 1973, el contexto internacional fue convulso. No menos complicada fue la situación española, donde concurrieron una serie de circunstancias que repercutieron negativamente en el crecimiento turístico: inestabilidad gubernamental; atentados terroristas -algunos contra intereses turísticos-; subida de la inflación; devaluación de la moneda -que supuso una crisis económica-; y la escasa inversión pública en infraestructuras relacionadas con el turismo. Todos estos hechos supusieron una quiebra del sector turístico que se vio afectada por un nuevo panorama (Bayón y Alonso, 1999). Esta inestabilidad tuvo una destacada consecuencia administrativa, ya que se suprimió el 4 de julio de 1977 el Ministerio de Información y Turismo, haciendo que las competencias en la materia de esta institución recayesen en la Secretaría de Estado de Turismo, creada el 8 de octubre de ese mismo año. Aunque, a priori, pudo parecer que la creación de este nuevo organismo la dotaba de cierta independencia y podía mejorar la situación de las políticas turísticas, el peso de esta en el ámbito político se vio mermado en relación a otros asuntos que se gestaron en esa situación de crisis que se prolongó hasta 1982. En este sentido, el aspecto legislativo también fue un factor de retroceso, ya que no se promulgaron importantes normas en materia turística (Moreno, 2007).

En este contexto, La Manga supo aprovechar esta circunstancia y se convirtió en una alternativa de reclamo turístico dentro de las ofertas de destino que habían presidido la etapa anterior (Moreno, 2007), pues su puesta en valor se produjo con retraso en relación a la mayoría de las localidades costeras mediterráneas, ya que la deficiencia de la red de carreteras no había permitido una fluida comunicación. Además, el crecimiento demográfico y económico de la zona gracias a las nuevas fórmulas implantadas en la agricultura no se produjo hasta los setenta (Vera, 1991). La expansión urbanística en La Manga estuvo justificada por las demandas del boom turístico con la creación de complejos hoteleros, la puesta en marcha de servicios relacionadas con el sector, la mejor en las vías de comunicación, la apertura de instalaciones deportivas y la construcción de segundas residencias. Todo ello, tuvo su correspondencia en las producciones de NO-DO que se hicieron eco de esta nueva situación.

\section{LA MANGA DEL MAR MENOR EN EL NO-DO}

La presencia de La Manga del Mar Menor, aunque se inicia en 1950, va a reflejar fundamentalmente el proceso de expansión ligado a la actividad turística que se dio desde finales de los sesenta hasta la supresión de este organismo estatal en 1981. La producción realizada durante este tiempo por NO-DO comprende nueve reportajes para el noticiario y dos documentales, uno perteneciente a la revista Imágenes, y el otro a la sección de Documentales (Tabla 1). Además de estos materiales en los que La Manga adquiere protagonismo, existen otros tres reportajes que recogen, casi de modo anecdótico, imágenes de este enclave, pero en estos casos su presencia se encuentra inmersa en otro contexto 5 .

$5 \quad$ Nos referimos a los pertenecientes a los números 1.611 A, 1.662 B y 1.761 B. 
Tabla 1

MATERIALES FÍLMICOS REALIZADOS POR NO-DO EN LA MANGA DEL MAR MENOR

\begin{tabular}{|c|c|c|c|c|}
\hline TÍTULO & $\begin{array}{c}\text { NÚMERO } \\
\text { DE NO-DO }\end{array}$ & AÑO & SECCIÓN & SONIDO \\
\hline EN EL MAR MENOR & 297 & 1950 & IMÁGENES & NO \\
\hline NOTICIAS ESPAÑOLAS & $1.271 \mathrm{~A}$ & 1967 & NOTICIARIO & SÍ \\
\hline $\begin{array}{c}\text { ESPAÑA EN DESARROLLO. } \\
\text { MURCIA }\end{array}$ & $1.407 \mathrm{~B}$ & 1969 & NOTICIARIO & SÍ \\
\hline DEPORTES & $1.557 \mathrm{~B}$ & 1972 & NOTICIARIO & SÍ \\
\hline MAR MENOR & $1.570 \mathrm{~B}$ & 1973 & NOTICIARIO & SÍ \\
\hline DEPORTES & $1.633 \mathrm{~A}$ & 1974 & NOTICIARIO & SÍ \\
\hline $\begin{array}{c}\text { IV SEMANA } \\
\text { INTERNACIONAL DE CINE } \\
\text { NAVAL DE CARTAGENA }\end{array}$ & $1.716 \mathrm{~A}$ & 1975 & NOTICIARIO & SÍ \\
\hline $\begin{array}{c}\text { CANCIONES PARA EL MAR } \\
\text { MENOR }\end{array}$ & $1.924 \mathrm{~A}$ & 1980 & NOTICIARIO & SÍ \\
\hline FAROS Y PESCA & $1.957 \mathrm{~B}$ & 1981 & NOTICIARIO & SÍ \\
\hline $\begin{array}{c}\text { UN PARAÍSO SACADO DE } \\
\text { LA MANGA }\end{array}$ & $1.958 \mathrm{~A}$ & 1981 & NOTICIARIO & SÍ \\
\hline \begin{tabular}{l} 
PESCA EN EL MAR MENOR \\
\hline
\end{tabular}
\end{tabular}

Fuente: Elaboración propia a partir de documentación de Filmoteca Española.

Los reportajes para el noticiario rodados en La Manga suman un total de 20 minutos y 8 segundos. El documental perteneciente a la revista Imágenes tiene una duración de 12 minutos y 43 segundos, mientras que el de la sección de documentales dura 10 minutos y 23 segundos. Las imágenes dedicadas a La Manga ocupan para las cámaras de NO-DO un total de 1 hora, 6 minutos y 8 segundos, una cifra significativa dentro de la realización regional, tal y como se muestra en el gráfico 1.

De estos datos, se desprende cómo La Manga fue uno de los focos que más interés despertó para la producción institucional, ya que, al comparar la cantidad de noticias y documentales rodados en esta zona con el resto de localidades regionales, se aprecia cómo ocupa el tercer lugar, solo por detrás de las dos grandes ciudades: la capital, Murcia, y Cartagena, que por su idiosincrasia reunía todos los ejes en torno a los que se articulaba el discurso del gobierno franquista (militar, industrial y religioso). El resto de lugares de la geografía murciana, exceptuando San Javier y Alcantarilla con un marcado carácter militar, tienen una presencia menos notable (Durante, 2014). 


\section{Gráfico 1 \\ DATOS DE PRODUCCIÓN POR LOCALIDADES}

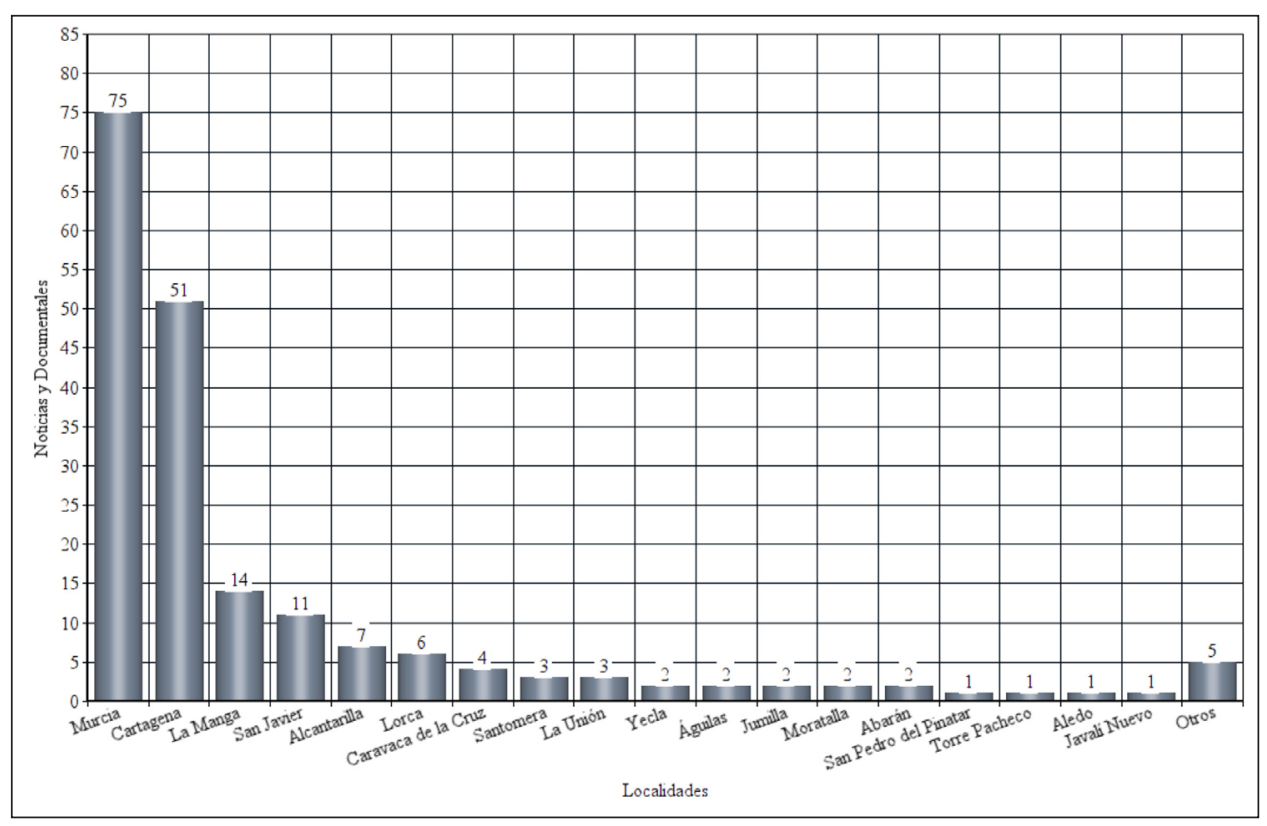

Fuente: Elaboración propia.

En cuanto a la cronología, como se ha señalado arriba, los años cincuenta fueron un tímido momento de apertura. Por ello, no es de extrañar que durante toda la década se haya constatado una representación cinematográfica de las cámaras de NO-DO en La Manga que hizo su aparición en el número 297 de la revista Imágenes, una sección caracterizada por la miscelánea de los temas tratado en los que la fijó una serie de pautas que marcaron la idiosincrasia de los diferentes territorios, es decir, se quisieron destacar los tópicos de cada lugar para exaltar sus señas de identidad. En los años sesenta se continúa esta tendencia, a diferencia de lo que estaba ocurriendo en otras zonas que ofertaban sol y playa, cuya imagen tuvo un mayor peso en estas fechas. En los años setenta, cuando La Manga toma el relevo a las sendas trazadas por el turismo nacional e internacional, su aparición en NO-DO es la más significativa de todo el periodo de realización de esta productora. En este sentido, el interés de difusión de este destino persistió hasta los últimos años de vida del noticiario. 


\section{Gráfico 2 \\ PRODUCCIÓN DE NO-DO POR DÉCADAS}

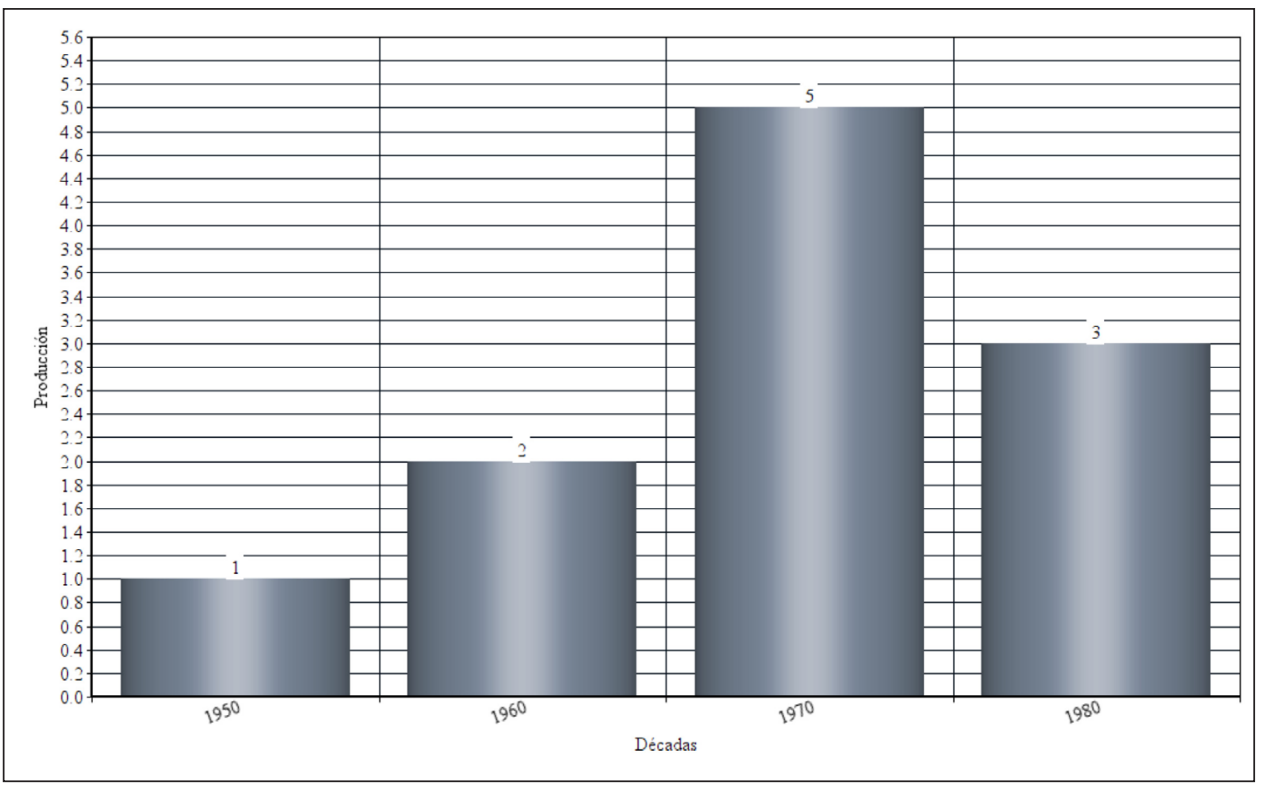

Fuente: Elaboración propia.

En otro orden de cosas, a partir del análisis iconográfico llevado a cabo de la imagen cinematográfica de La Manga del Mar Menor en NO-DO, hemos constatado una serie de denominadores que fueron recurrentes y que se erigieron, por un lado, como elementos definidores de ese espacio y, por otro, como factores diferenciadores de reclamo turístico que la distinguieron de otros destinos. Estas constantes se concretan en los siguientes puntos:

\subsection{La construcción de La Manga como mito turístico}

El interés por hacer de La Manga del Mar Menor un mito turístico se determinó ya en las primeras imágenes cinematográficas que recogieron el aspecto virgen del entorno natural donde la mano del hombre apenas había tenido presencia. Las ventajas territoriales que harían de esta zona un destino preferente dentro de la oferta turística de sol y playa fueron puestas de relieve en el documental no 297 para Imágenes rodado en 1950 que, a través del uso de planos generales aéreos, recogió una visión topográfica del enclave; una cuestión formal de la que haría uso el noticiario en los distintos números dedicados a La Manga para resaltar sus singularidades. Las imágenes de este primer documental difieren de las que posteriormente NO-DO se encargaría de producir. En este sentido, en pleno auge turístico de esta zona, los números 1.407 B (1969), 1.570 B (1973), 1.957 B (1981) y el documental Canciones para el Mar Menor (1978) 
contribuyeron a construir y difundir una idea de paraíso que se fundamentó, por lado, en mostrar un entorno de relax, sin playas masificadas, y de mar en calma con poca profundidad, que garantizaba la seguridad de los bañistas y, por otro lado, en destacar las posibilidades de recreo y diversión con las que desconectar en los periodos vacacionales, a través de una narrativa tanto visual como textual. En este sentido, el n ${ }^{\circ} 1.407$ B fue la primera ocasión en la que se expuso la idea de paraíso por medio de distintas vistas panorámicas, que fueron acompañadas del siguiente texto: "Las palmeras y el agua componen un paisaje dulce y sedante para el ajetreado hombre de nuestro tiempo (...) Sobre el perfil romántico de los acantilados, las playas, los peñones y las albuferas se afirma con personalidad singular la estampa serena de La Manga del Mar Menor, que envaina el agua como un fino puñal templado por todas las luces del mediterráneo. 220 días de cielo azul, año tras año, en esta costa que es un verdadero paraíso". En esta línea, también la locución del $\mathrm{n}^{\circ} 1.570$ B ensalzó la climatología, expresándose de manera lírica: "aquí se goza de un clima de excepción durante todo el año, pues los inviernos se ven suavizados por la proximidad del Mar Menor, ese lago natural que almacenando los rayos solares actúa como un inmenso termo natural". Junto a ello, se reflejó La Manga como un espacio de relax, mostrando imágenes de los veraneantes en los modernos hoteles recién inaugurados, mientras tomaban el sol, se bañaban en la piscina o contemplaban el mar. Llama la atención cómo la cámara encuadra a las turistas en bikini, algo insólito para los parámetros de decoro que habían marcado las políticas de moralidad franquistas en los años precedentes. De hecho, en la década de los cincuenta, se dictaron una serie de normas respecto a indumentaria, decoro y comportamiento de los turistas (Pack, 2009).

La promoción paradisiaca de La Manga no solo encontró en las imágenes en movimiento un vehículo de difusión, sino también en algunas de las cabeceras que servían de entradilla al reportaje. En el $\mathrm{n}^{\circ} 1.957 \mathrm{~B}$, a modo de preludio, la cabecera fue una declaración de intenciones de la representación de la imagen de La Manga en el imaginario colectivo (Fig. 1), así como la voz en off que subrayó las imágenes: “(...) La Manga del Mar Menor nos ofrece una demostración singular del esfuerzo del hombre por dominar la naturaleza y convertir un desierto, hostil y olvidado, en un verdadero paraíso".

Por último, en el documental Canciones para el Mar Menor confluyeron las dos bases que cimentaron la idea de paraíso: el relax y la diversión. Esta narración se estructura en torno a tres canciones interpretadas por célebres cantantes de la época. Los temas de Ángela Carrasco y Paloma San Basilio entroncan con ese concepto del descanso, con una balada, en el primero de los casos, de imágenes sugerentes donde se busca la belleza de las vistas que se encuadra dentro del gusto por señalar ese rincón de calma y tranquilidad. Esa misma intención, aunque con un corte más pop, es la que tiene Paloma San Basilio, a la que sumó la imagen de diversión y recreo, que alcanza su canto de cisne en la sorprendente interpretación de Miky con constantes referencias al mundo de la droga.

Todos estos factores que articularon los contenidos fílmicos afianzaron la construcción del mito de La Manga del Mar Menor que entroncó con la idea de paraíso (Cardona, Azpelicueta y Serra, 2015). El propósito de generar, pues, un icono de descanso se vio favorecido por la labor que desde NO-DO se realizó a lo largo de toda su vigencia. 
Figura 1

CABECERA No $1.957 \mathrm{~B}$

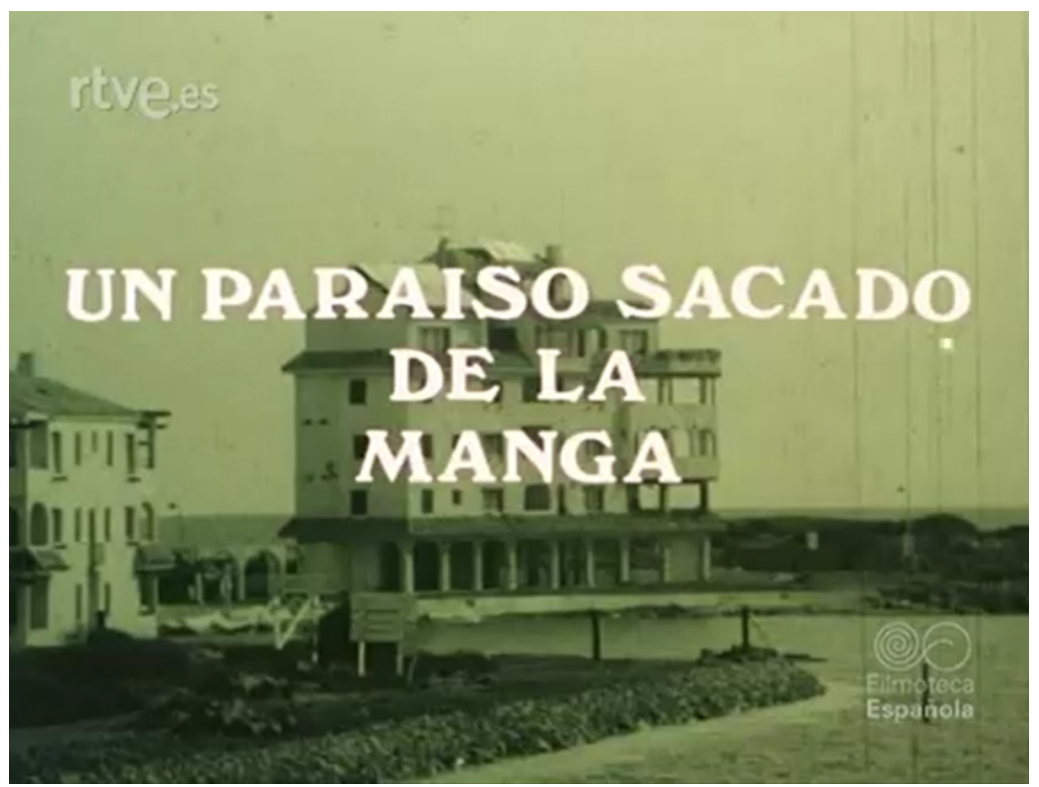

Fotograma del no 1.957 B del noticiario cinematográfico NO-DO.

\subsection{La creación de infraestructuras y servicios para un destino vaca- cional}

La puesta en marcha de instalaciones destinadas a las demandas turísticas de La Manga fue un factor primordial para la creación de una oferta en el mercado del sector. En 1967 se inauguran los hoteles más importantes de la zona. Durante esta década fue la oferta hotelera la que primó. Así, vemos en el número 1.271 A, la llegada de las autoridades nacionales a los nuevos complejos. La importancia de la renovación de las infraestructuras tuvo tal calado que incluso Manuel Fraga Iribarne, entonces Ministro de Información y Turismo, se desplazó para asistir a la inauguración, acompañado de Tomás Maestre, León Herrera Esteban, Director General de Empresas y Actividades Turísticas y Luis Navarro Garnica, General Jefe del Estado Mayor del Aire (Fig. 2). Este reportaje recoge las visitas a los hoteles Entremares y Galúa, a la urbanización Dos Mares, en fase de construcción, y al nuevo Puerto Deportivo del Mar de Cristal, también en construcción. Esta no es la única ocasión en la que los hoteles fueron objetivo de las cámaras de NO-DO. También el número $1.407 \mathrm{~B}$ recoge distintas urbanizaciones -algunas en construcción y otras recientemente inauguradas-, además de los hoteles Entremares y Galúa, los cuales en el número 1.570 B y en el documental Canciones para el Mar Menor, ya se muestran concurridos por los veraneantes que pasan sus horas de asueto en las diferentes instalaciones. En 
los años setenta, por otra parte, la segunda residencia tomó el relevo a la oferta hotelera (García, Artal y Ramos, 2002). Esto se constata en el número 1.924 A, donde aparecen las nuevas urbanizaciones como la de "El pescador", señalando la modernización de estas construcciones con la inclusión de paneles solares para el autoabastecimiento de energía. Asimismo, también se incluyeron en las noticias y documentales distintos servicios para los turistas como supermercados, lugares de ocio -discotecas o bingos-, o instalaciones deportivas. Más tarde en los años 80, la estampa de La Manga vendría determinada por el desarrollo urbanístico alineado a lo largo de la restinga. A este respecto, el número 1.957 B se hace eco de esa nueva ordenación territorial, mostrando diferentes vistas áreas con los edificios, locales de ocio, como el Casino, las urbanizaciones y otras instalaciones comerciales y de servicios.

\section{Figura 2 \\ INAUGURACIÓN DEL HOTEL ENTREMARES}

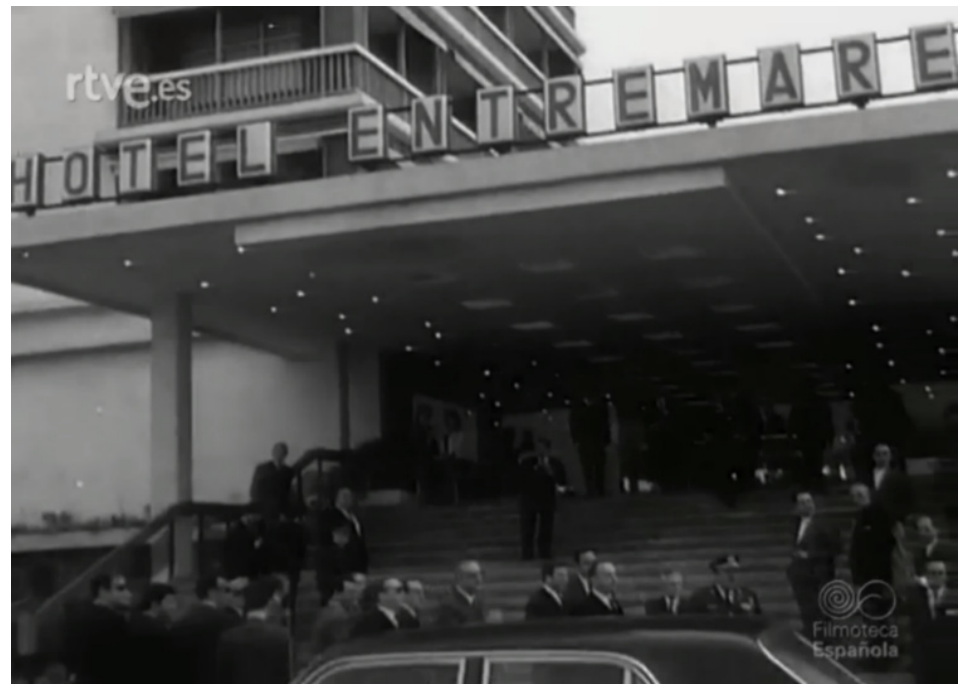

Fotograma del $\mathbf{n}^{0} 1.271$ a del noticiario cinematográfico NO-DO.

\subsection{La promoción deportiva}

El ámbito del deporte fue otro de los potenciales del turismo de La Manga, que supo estructurar su oferta en dos vertientes: la amateur y la profesional. Fueron fundamentalmente dos los ejes en los que el deporte tuvo una mayor relevancia; como es evidente, los deportes náuticos, beneficiados por las buenas condiciones que reúne este mar interior, y el golf. Respecto a los primeros, las actividades fueron de índole diversa, así NO-DO difundió la práctica del esquí acuático, la vela o la pesca submarina o la deportiva como muestran los números 1.958 A y $1.570 \mathrm{~B}$. En este último, además, se pueden ver otras actividades deportivas como el tenis, la hípica o el tiro al pichón. Pero, sin lugar a duda, el que mayor interés 
despertó fue el golf, contando con uno de los campos más importantes de Europa, que fue inaugurado en 1972 con una extensión de 115 hectáreas para 36 hoyos, que fue dotado de sistemas de drenaje, irrigación y lagos artificiales. Por ello, no es de extrañar que las referencias de NO-DO a este campo fuesen habituales en los distintos reportajes y documentales (1.557 B, 1.570 B, 1.633 A y Canciones para el Mar Menor). Algunos de los importantes eventos que se organizaron en este campo de golf fueron recogidos por NO-DO, como el 48 Campeonato Abierto de Golf de España en el que participaron 23 países.

\subsection{Las celebridades como reclamo turístico}

Uno de los recursos más frecuentes para la promoción turística fue, y sigue siendo, la presencia de celebridades. La Manga encontró en los eventos culturales y deportivos la plataforma perfecta para implementar su imagen con conocidos actores y deportistas que ayudaron a promocionar el destino. Entre ellos, encontramos figuras como Sean Connery, Manuel Santana o Sydney Chaplin (1.557 B y 1.570 B). Además, también hay referencias a la visita de actrices al campo de golf en otros reportajes relacionados con la Semana Internacional de Cine Naval de Cartagena, donde los invitados por una cuestión de proximidad y estatus visitaban este enclave. A este respecto, el número $1.611 \mathrm{~A}$, que forma parte de la selección en la que La Manga aparece de manera anecdótica, nos muestra a las actrices Carmen de la Maza y Guira María paseando por el campo de golf. También los cantantes de moda en ese momento, Ángela Carrasco, Miky y Paloma San Basilio, intervinieron en el documental Canciones para el Mar Menor.

\section{Figura 3 \\ SEAN CONNERY, GREGORY PETERS Y VALENTÍN BARRIOS}

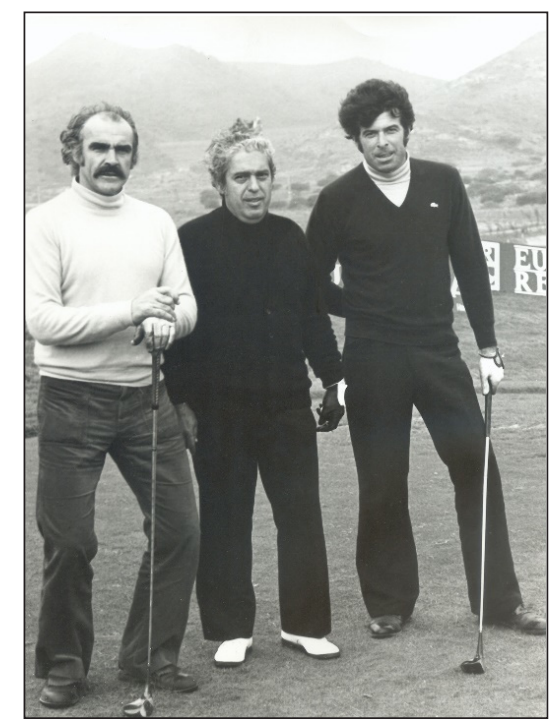

Fotografía del actor junto a golfistas en La Manga Club (años 70). 


\subsection{La tradición pesquera en el Mar Menor}

La actividad pesquera fue una de las principales de la economía de La Manga desde sus orígenes y por ello fue uno de los aspectos presentes en las producciones cinematográficas de NO-DO. Ya desde el primer documento fílmico, número 297 de la revista Imágenes (1950) se dejó constancia de su significación en la cabecera que dio entrada al documental, donde a modo de preludio aparecía el título sobreimpreso a una representación pictórica del Mar Menor en la que se resaltaba la importancia de la actividad pesquera, el deporte náutico, al tiempo que se hacía patente la presencia de embarcaciones y aeronaves militares. En esta suerte de síntesis de los rasgos definidores del Mar Menor, en ese momento, cobró especial interés la práctica pesquera que fue mostrada a través de uno de los parámetros idiosincrásicos, como fueron las encañizadas, un sistema tradicional de pesca en la zona, donde las cámaras se detuvieron en recoger el proceso de captura de doradas y boquerones, dos especies típicas de este enclave. Estas imágenes de las vistas casi salvajes se contraponen con la narrativa cinematográfica que nos ofrecen el resto de localidades del Mar Menor, como Los Alcázares o San Javier, que asumieron un perfil donde estuvo presente la huella de lo militar. En este número, la presentación de las encañizadas se articula con un carácter lírico generado a partir del punto de vista de la cámara que recoge el sosiego del mar en calma y que da una visión casi romántica de la pesca. Esto se consigue a través de la utilización de planos generales intercalados con otros planos detalle, a lo que se suma el uso del paneo. Así, el reflejo de la tradición autóctona se completa con imágenes de la industria salinera de San Pedro del Pinatar a través de estampas donde aparece parte del trabajo, como el traslado con vagonetas de hierro sobre raíles tiradas por mulas.

A tenor de lo señalado en relación con el valor de la tradición, debemos apuntar que el Régimen en sus deseos de legitimarlo consolidó la representación de la iconografía de la actividad pesquera a lo largo de las producciones realizadas en las sucesivas décadas, manteniéndose incluso con el advenimiento de la democracia. Así lo demuestran los números 1.570 B o 1.924 A. En este último caso, precisamente titulado Faros y pesca, vuelve a mostrarse el arraigo de esta actividad y su peculiar sistema de encañizadas. Además, en la locución se vincula esta tradición con el turismo: «subsiste el viejo oficio marinero en simbiosis con el turismo y los arcaicos laberintos de cañizos perduran ante las urbanizaciones tan avanzadas como la de El Pescador». También el número 1958 A reincide, en la línea del anterior, en mostrar la tradición pesquera propia de zona. Bajo el título de Pesca en el Mar Menor se centra en contextualizar históricamente la peculiaridad de las encañizadas, cuyo origen se remonta, como el propio texto apunta, a la Edad Media.

Incluso en el documental Canciones para el Mar Menor, fundamentalmente de carácter musical, a través de intervalos se articula una reflexión sobre los elementos de transformación que operan desde la tradición a lo modernización de la zona. La práctica pesquera, a este respecto, se erige como uno de los factores esenciales presentes en esa evolución.

En otro orden de cosas, analizando los valores formales y expresivos, se pueden establecer una serie de concomitancias con el cine neorrealista, ya que la intención de representación de la realidad de este movimiento concuerda con los rasgos del documental. Por tanto, las imágenes relacionadas con la pesca se revelan deudoras, en cuanto al montaje, 
la planificación y la estética, de aquellas que ofrecieron directores como Rosellini. La secuencia de la pesca del atún de la película Stromboli, terra di dio (R. Rosellini, 1950), por ejemplo, guarda evidentes paralelismos con las propuestas de NO-DO en los reportajes y documentales de La Manga.

\section{Figura 4 \\ ENCAÑIZADAS}

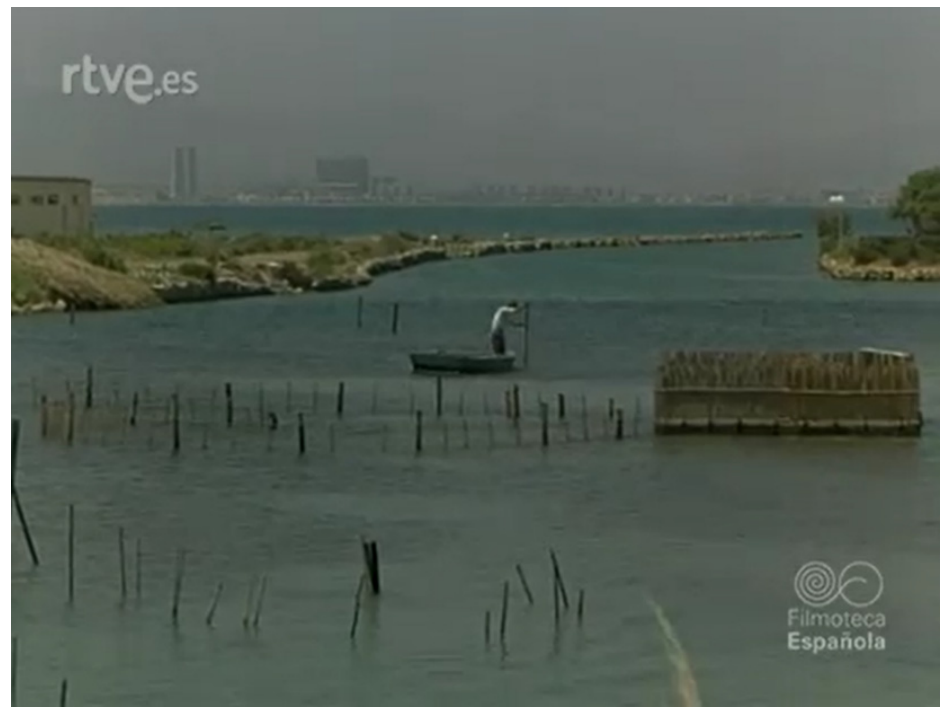

Fotograma del documental Canciones para el Mar Menor.

\section{CONCLUSIONES}

La configuración iconográfica que definió el imaginario de La Manga estuvo determinada por la reiteración de una serie de temas y elementos que propiciaron la construcción de un semblante propio y característico que hizo de este destino uno de los más excepcionales en nuestro país. Fueron diversas las constantes temáticas de las que se sirvió la cinematografía oficial para canalizar el mito de La Manga. Por un lado, las singularidades territoriales del enclave, caracterizadas por el buen clima, las especiales condiciones marítimas y los rincones paradisíacos. A estas peculiaridades se incorporaron la construcción de infraestructuras y la dotación de servicios para los veraneantes, como insistieron en promocionar las cámaras de NO-DO, sobre todo, haciendo hincapié en la oferta deportiva, no sólo náutica sino, fundamentalmente, de golf. En este ámbito se realizó una destacada promoción a partir de figuras relevantes dentro de sectores como el cine o el propio deporte que reforzaron la difusión de La Manga en el territorio nacional. Además, la presencia de autoridades como ministros y cargos afines al gobierno, con motivo de inauguraciones 
relacionadas con el sector hotelero y de servicios, apuntala esta idea. Por otro lado, siempre estuvo presente la tradición, a través de los números que dedicaron sus imágenes a representar la actividad pesquera y la idiosincrasia de un sistema como el de las encañizadas.

Desde el punto de vista cuantitativo, se han contabilizado en este estudio once películas, entre noticiarios y documentales, que centran su objetivo en La Manga, lo que supone una cifra significativa de la producción total rodada en la Región de Murcia. Ello demuestra el interés de este entorno, cuya evolución estuvo determinada por el crecimiento y la planificación urbanística, así como por la diversificación en la oferta de servicios destinada al turismo de sol y playa.

Precisamente, el turismo se erigió como uno de los asuntos vertebradores del discurso franquista a partir de los años sesenta, momento en el que comenzó su transformación La Manga. Sin embargo, esta localidad demoró su despegue turístico a la década posterior, los años setenta, un momento de crisis a nivel internacional que, sin embargo, supo aprovechar para posicionarse como uno de los destinos predilectos de los veraneantes, tal y como se constata en la amplia producción de NO-DO.

En el apartado formal, los documentales y noticias se centraron en la representación de La Manga a través de un lenguaje caracterizado por el uso de planos aéreos y paneos, intentando proporcionar una visión de conjunto de la condición endógena del territorio antes señalada. Ambos formatos siguieron una construcción discursiva similar, a partir de estos parámetros visuales, consagrando unos códigos narrativos comunes a la representación de la imagen turística.

El cine contribuyó, de este modo, a consolidar la idea de marca de destino potenciando las ventajas de la oferta que fueron el vehículo idóneo para construir la mirada turística, una circunstancia que se consolidó tras la creación del Ministerio de Información y Turismo, bajo cuya denominación convergieron los dos intereses que promocionó NO-DO. No obstante, las directrices políticas que marcaron las producciones cinematográficas tuvieron un manifiesto cariz ideológico que respondió a intereses de orden nacional y que sirvieron para construir la imagen de España.

\section{BIBLIOGRAFÍA}

AFINOGUÉNOVA, E. y MARTÍ-OLIVELLA, J. (2008): Spain is (still) different: tourism and discourse in Spanish identity. Lanham, MD, Lexington Books.

ANDRÉS SARASA, J.L. (1995): «La gente es consumidora de mitos... el mito turístico en el Mar Menor», Papeles de Geografía, n 22, pp. 5-17.

BAYÓN MARINÉ, F. y ALONSO SUTIL, M.C. (1999): 50 años del turismo español. Un análisis histórico y estructurado. Madrid, Centro de Estudios Ramón Areces/Escuela Oficial de Turismo.

BROTONS CAPÓ, M. M., MURRAY-MAS, I, y BLÁZQUEZ-SALOM, M. (2016): «Viaje de ida y vuelta, al mito. La contribución del cine a la formación de la iconografía turística de Mallorca», Anales de Geografía, vol. 36, n 2, pp. 203-236.

CARDONA, J.R., AZPELICUETA CRIADO, M.C. y SERRA CANTALLOBS, A. (2015): «El mito del paraíso perdido en la definición del destino turístico», Estudios y Perspectivas en Turismo, Vol. 24, n 3, pp.715-735. 
DEL AMO GARCÍA, A. (1993): «El noticiario NO-DO», Archivos de Filmoteca, Valencia, Ediciones de la Filmoteca, $\mathrm{n}^{\mathrm{o}} 15$.

DURANTE ASENSIO, I. (2014): Retóricas de la nostalgia: Imagen, propaganda e identidad. Los reportajes y documentales del NO-DO en la Región de Murcia. Tesis Doctoral. Universidad de Murcia.

ESPEJO, C. (2011): «Innovación para la competitividad turística de La Manga del Mar Menor (Murcia)», Cuadernos de Turismo, no 27, pp. 321-339.

GALIANA MARTÍN, L. y BARRADO TIMÓN, D. (2006): «Los centros de Interés Turístico Nacional y el despegue del turismo de masas en España», Investigaciones Geográficas, n 39, pp. 73-93.

GARCÍA SÁNCHEZ, A., ARTAL TUR, A. y RAMOS PARREÑO, J. M. (2002): «El turismo del Mar Menor: predominio de la segunda residencia», Cuadernos de Turismo, $\mathrm{n}^{\circ}$ 9, pp. 33-43.

MATUD, A. (2008): «El cine documental franquista: introducción a la producción de documentales de NO-DO», I Congreso Internacional de Historia y Cine (1, 2007, Getafe). Getafe, Universidad Carlos III de Madrid/Instituto de Cultura y Tecnología, pp. 516-527.

MORENO GARRIDO, A. (2007): Historia del turismo en España en el siglo XX. Madrid, Síntesis.

PACK, S. D. (2009): La invasión pacífica. Los turistas y la España de Franco. Madrid, Turner.

RILEY, R.W. y VAN DOREN, C. S. (1992): «Movies as tourism promotion», Tourism Management, vol. 13, $\mathrm{n}^{\circ} 3$, pp. 267-274.

RODRÍGUEZ, S. (1999): El NO-DO, Catecismo social de una época. Madrid, Editorial Complutense.

RODRÍGUEZ TRANCHE, R. y SÁNCHEZ-BIOSCA, V. (2005): NO-DO. El tiempo y la memoria. Madrid, Cátedra/Filmoteca Española.

URRY, J. (1990): The tourist gaze: leisure and travel in contemporary societies. Londres, Sage Publications.

VERA REBOLLO, J.F. (1991): «El turismo», en Atlas Región de Murcia. Murcia, Comunidad Autónoma y La Opinión, pp. 301-312.

ZAMARREÑO, G. (2010): «Cine y turismo en la Costa del Sol. Retrato de unos colonizados», en SAURET GUERRERO, M. T. (coord.), Usos, costumbres y esencias territoriales. Málaga, Ministerio de Ciencia e Innovación: Universidad de Málaga, Servicio de publicaciones, pp. 581-598.

ZAMARREÑO, G. y DE LOS REYES, E. (2017): «Málaga y la marca territorio en el cine del turismo del franquismo», International Journal of Scientific Management and Tourism, vol.3, $\mathrm{n}^{\circ} 3$, pp. 541-564. 